\title{
PARTICIPAÇÃO DO MYCOPLASMA PNEUMONIAE NA ETIOLOGIA DE INFECÇÕES RESPIRATÓRIAS AGUDAS EM RIBEIRÃo PRETO, SÃO PAULO, BRASIL.
}

\author{
Alcyone A. Machado, Robert B. Couch, Antonio Joaquim Rossini \\ e João Carlos da Costa
}

\begin{abstract}
Para a valiar a participaçāo etiológica do Mycoplasma pneumoniae em infecçòes respiratórias agudas, o isolamento dess a bactéria foi tentado em secreções do aparelho respiratório de 64 pacientes (média 24 anos) com quadro respiratório agudo. Foi realizada, também, a pesquisa de anticorpos específicos anti-M. pneumoniae através da reação de fixação do complemento $(F C)$ e da reação de contra-imunoeletroforese (CIE). $O \mathrm{M}$. pneumoniae não foi isolado. $O$ diagnóstico presuntivo de infeçāo pelo M. pneumoniae foi feito pela $F C$ em 3,1\% (2/64) e pela CIE em 1,6\% (I/64) dos pacientes. Paralelamente, em 200 individuos sadios, os mesmos testes sorológicos foram realizados, sendo o indice de positividade de $4 \%(8 / 200)$ pela CIE e de $1 \%(2 / 200)$ pela FC. Apesar das discrepancias observadas entre os dois métodos sorológicos, a $F C$ parece ser indicada para diagnóstico da infeç̧ão, sendo a CIE recomendada nas avaliaçōes soroepidemiológicas. Com base nos dados do nosso estudo, a prevalência das infecçoes respiratórias pelo M. pneumoniae parece ser baixa em nosso meio.
\end{abstract}

Palavras-chaves: Infeções respiratórias. Mycoplasma pneumoniae. Pneumonias por micoplasma. Prevalência do Mycoplasma pneumoniae.

Os micoplasmas são considerados os menores microrganismos de vida livre 4041 , podendo apresentar-se como saprófitas ou causando doenças. Entre os micoplasmas que podem causar doença no homem encontra-se o $M$. pneumoniae ${ }^{6}{ }^{40}$, que está relacionado com infecção respiratória aguda, incluindo-se as pneumonias.

Geralmente a infecção pelo $M$. pneumoniae tanto no trato respiratório alto como baixo é clinicamente indistinguível da causada por outros agentes, como outras bactérias e vírus, sendo necessário recorrer-se a métodos laboratoriais, tais como o isolamento mediante cultivo de secreção do nasofaringe, "swab" de orofaringe, simples amostra de escarro ou lavado brônquico 1040 e/ou demonstração da presença de anticorpos específicos no soro.

Anticorpos podem ser demonstrados e quantificados por diferentes métodos, entre eles a reação de fixação de complemento, (FC) que é considerada uma

Faculdade de Medicina de Ribeirão Preto da Universidade de São Paulo, Ribeirão Preto, São Paulo.

Influenza Research Center, Baylor College of Medicine, Texas Medical Center, Houston, Texas 77030, USA.

Faculdade de Medicina Veterinária e Zootecnia da Universidade de São Paulo, Pirassununga, São Paulo.

Endereço para correspondência: Dra. Alcyone A. Machado, Depto. de Clínica Médica, Hospital das Clínicas/FMRP/USP. 14048 Ribeirão Preto, SP, Brasil.

Recebido para publicação em 20/11/90. das mais sensiveis 33840434546 . Mais recentemente a contra-imunoeletroforese (CIE) foi aplicada para detectar anticorpos anti-M. pneumoniae ${ }^{21}$.

A literatura é repleta de estudos sobre a ocorrência da infecção pelo $M$. pneumoniae em várias regiões do mundo 320233739 , sendo, porém, escassa no Brasil 343643 , principalmente a respeito do seu comportamento epidemiológico em populações de adultos jovens. Nesse sentido propõe-se:

1. Estudar a participação etiológica do $M$. pneumoniae em infecções respiratórias agudas, em individuos com 3 a 40 anos de idade, através da tentativa de isolamento do $M$. pneumoniae em secreçōes do aparelho respiratório e da pesquisa de anticorpos especificos contra essa bactéria em amostras pareadas de soro, por fixação de complemento (FC) e contra-imunoeletroforese (CIE), correlacionando os resultados assim obtidos com idade, cor, condições de moradia, história, exames clínicos, antecedentes alérgicos e outros dados dos pacientes.

2. Analisar e correlacionar os resultados obtidos pelos métodos sorológicos que utilizamos no diagnóstico da infecção por $M$. pneumoniae.

3. Estudar a prevalência de anticorpos contra $M$. pneumoniae em Ribeirão Preto-SP, em uma população aparentemente isenta de infecção respiratória aguda, através de mesmos métodos sorológicos (FC e CIE). 


\section{MATERIAL E MÉTODOS}

A população de estudo constou de 64 pacientes, de 3 a 40 anos de idade, residentes em Ribeirão Preto, que procuraram o Hospital das Clínicas da Faculdade de Medicina de Ribeirão Preto- Universidade de São Paulo(HCFMRP-USP) no periodo de agosto de 1985 a setembro de 1986 com comprometimento respiratório diagnosticado clínico-radiologicamente como broncopneumonia, pneumonia lobar, pneumonia intersticial, traqueobronquite e acometimento de vias respiratórias superiores. Foram selecionados os três primeiros pacientes, durante a semana, com queixas de um ou mais dos seguintes sintomas: tosse, dor de garganta, coriza, associados ou não a febre, por período de até 3 semanas. Esses pacientes foram submetidos à anamnese e exame físico completos.

A populaçāo-controle constou de 200 amostras de soro (100 do sexo masculino - candidatos à doação de sangue no HCFMRP-USP - e 100 do sexo feminino - funcionárias do HCFMRP-USP) de indivíduos sadios, sem história recente de infecção respiratória aguda, procedentes de Ribeirão Preto e com faixa etária semelhante à da população do estudo. As amostras foram submetidas aos testes de FC e CIE utilizando-se a mesma bateria de reagentes da população do estudo.

Para o isolamento do $M$. pneumoniae de cada doente (população de estudo) foram colhidos:

1. escarro, em recipiente estéril

2. secreção de orofaringe, através de "swab" utilizando-se cotonete (manufaturado no próprio laboratório).

Esses materiais foram colhidos antes de terapia antimicrobiana e encaminhados imediatamente ao laboratório, sendo semeados em meios sólidos e líquidos, seguindo-se o preconizado pelo manual do "Naval Medical Research Unit no 4"9. Os meios sólidos observados por 2, 4, 7, 10, 14, 21 e 30 dias em que não houve crescimento de colônias sugestivas de M. pneumoniae foram considerados negativos. Caso houvesse crescimento de colônia suspeita eram realizadas provas de caracterização: coloração de Dienes, hidrólise de arginina e a formação de manchas e filmes ${ }^{9}$.

Todos os meios de cultura em uso, tanto sólidos como líquidos, foram conferidos periodicamente pela cepa "Mac" de $M$. pneumoniae cedida pelo Instituto Adolfo Lutz de São Paulo.

Para a pesquisa de anticorpos anti $M$. pneumoniae foram colhidas de cada doente duas amostras de $10 \mathrm{ml}$ (periodo agudo e de convalescença) com intervalo médio de 20 dias ( 14 a 59 dias). Essas amostras foram processadas pareadas.
Tanto as amostras da população de estudo quanto as da população-controle sofreram, um dia antes dos testes FC, pré-tratamento, com a finalidade de prevenir a possivel detecção de realizações anticomplementares 26 . O soro assim tratado já se encontrava na diluição de 1:8.

A FC foi realizada por micrométodo ${ }^{30}$, sempre utilizando-se um soro positivo e negativo conhecidos, como controles da reação. Faziam-se diluiçōes seriadas de 1:16 a 1:64. O teste era considerado positivo quando ocorria hemólise parcial ou se não ocorresse hemólise; o teste era considerado negativo quando houvesse hemólise total.

Como critérios para análise dos dados relativos à $\mathrm{FC}$ consideraram-se:

1. A prova de FC padrão, que mostrasse elevação do título do quádruplo ou mais, em amostras de sangue colhidos na fase aguda e na convalescença, permitindo o diagnóstico de infecção atual ou recente por M. pneumoniae.

2. Título isolado maior ou igual ( $\geqq$ a 64 era altamente sugestivo dessa infecção, no caso da não disponibilidade de amostras pareadas.

3. Título menor ou igual (\) a 8 , interpretado como negativo, e sem valor para o diagnóstico sorológico de infecção em fase aguda pelo $M$. pneumoniae; título de 16 foi interpretado como título baixo e o de 32, como intermediário.

Para a realização da CIE utilizou-se a técnica descrita por Edwards ${ }^{11}$ e Greenwood e cols 22 , que é a empregada na rotina do laboratório de sorologia do HCFMRP-USP, com modificações feitas por Levy 28 e Rossini ${ }^{42}$. Em todas as reações foram usados um soro positivo e um negativo conhecidos como controles. Faziam-se diluições seriadas a partir de 1:1. O teste foi considerado positivo quando havia presença de linhas de precipitação e negativo na ausência das mesmas. Como critérios para a análise dos dados relativos à CIE estabeleceu-se que:

1. Amostras pareadas da fase aguda e da convalescença, que mostrassem elevação do titulo ao quádruplo ou mais, permitia o diagnóstico presuntivo de infecção pelo $M$. pneumoniae.

2. A não presença de linhas de precipitação na reação no soro puro foi interpretada como negativa.

$\mathrm{O}$ antigeno empregado tanto na FC como na CIE foi cedido pelo Dr. Robert B. Cough do Baylor College of Medicine, Houston, Texas, E.U.A.

Após a colheita dos materiais acima referidos, cada paciente foi observado para o diagnóstico de infecção respiratória em sua fase aguda e submetido a eventual tratamento especifico e/ou sintomático, segundo a rotina vigente neste hospital.

Amostras de escarro e/ou secreção de orofaringe e/ou de sangue de cada paciente também sofre- 
Machado AA, Couch RB, Rossini AJ, Costa JC. Participação do Mycoplasma pneumoniae na etiologia de infeções respiratórias agudas em Ribeirāo Preto, São Paulo, Brasil. Revista da Sociedade Brasileira de Medicina Tropical 24: 43-50, jan-mar, 1991

ram processamento, segundo rotina vigente no hospital, quanto à cultura para isolamento de outros possiveis agentes etiológicos bacterianos que não o $M$. pneumoniae.

\section{RESULTADOS E DISCUSSÃO}

A população de estudo constou de 64 pacientes, sendo 25 do sexo masculino, 39 do sexo feminino, 20 não brancos e 44 brancos.

A idade média foi de 24 anos (variação de 3 a 40 anos). Houve predomínio de pacientes com 15 a 29 anos. Seis pacientes tinham menos que 10 anos e dois menos de 5 anos, nos quais não houve isolamento do agente e/ou demonstração de anticorpos séricos antiM. pneumoniae pelos métodos empregados. A análise ficou prejudicada pelo fato de a população estudada ser pequena.

$\mathrm{Na}$ população de estudo encontrou-se quadro clínico e radiológico compativel com pneumonia bacteriana em 42 pacientes, pneumonia de etiologia a esclarecer em 2, traqueobronquite em 6 e de provável "quadro viral" em 9. Em um paciente só posteriormente foi feito o diagnóstico de tuberculose pulmonar, com o encontro de BAAR no exame direto do escarro. Em dois pacientes que apresentavam inicialmente quadro respiratório e febre foi feito o diagnóstico clinico de sinusite e amigdalite.

Em 11 pacientes foram encontradas outras bactérias que não o $M$. pneumoniae, que eventualmente poderiam estar implicadas como agentes responsáveis pela sintomatologia (Tabela 1).

Tabela I - Isolamento em meios de cultura apropriados de outros agentes etiológicos que nāo M. pneumoniae em II pacientes com IRA atendidos no HCFMRP-USP.

\begin{tabular}{|c|c|c|c|}
\hline $\begin{array}{c}\text { Paciente } \\
\text { n. }^{\circ}\end{array}$ & $\begin{array}{l}\text { Cultura de escarro em } \\
\text { ágar sangue e NI }\end{array}$ & Hemocultura & Observações \\
\hline 1 & E. coli & nff & - \\
\hline 4 & E. coli & negativa & $\begin{array}{l}\text { cultura de líquido pleural em ágar } \\
\text { sangue negativa. }\end{array}$ \\
\hline 17 & $\begin{array}{l}\text { S. aureus } \\
\text { K. pneumoniae }\end{array}$ & $\begin{array}{l}\text { S. pneumoniae } \\
\text { (2 amostras) }\end{array}$ & - \\
\hline 18 & S. pneumoniae & nff & - \\
\hline 19 & S. pneumoniae & nff & - \\
\hline 26 & $\begin{array}{l}\text { S. aureus } \\
\text { S. pneumoniae }\end{array}$ & negativa & - \\
\hline 28 & negativa & negativa & $\begin{array}{l}\text { M. tuberculosis em pesquisa direta } \\
\text { e cultura do escarro. Paciente toxi- } \\
\text { cômana. Teste anti-HIV: nff. }\end{array}$ \\
\hline 30 & $\begin{array}{l}\text { S. viridans } \\
\text { S. epidermidis }\end{array}$ & nff & - \\
\hline 34 & S. pneumoniae & $\mathrm{nff}$ & - \\
\hline 38 & K. pneumoniae & negativa & - \\
\hline 48 & negativa & S. aureus & $\begin{array}{l}\text { toxicomano; teste anti-HIV: nega- } \\
\text { tivo. }\end{array}$ \\
\hline
\end{tabular}

nff = não foi feito; NI = NAITO (meio em cuja constituição participa o cloreto de sódio, idealizado pela Profa. Dra. Isabel Ito. Fac. Farmácia Rib. Preto-USP); no = número; IRA = infecção respiratória aguda.

Não foi isolado $M$. pneumoniae de nenhum dos materiais cultivados. Os insucessos podem estar relacionados a fatores de inibição ou ação inibidora de lisolecitinas, enzimas lisossômicas, anticorpos e resíduos de antibióticos nas secreções do trato respiratório ${ }^{31}$ ou contaminantes no material os quais competiriam pelos substratos 25 . Colocaram-se descontaminantes no preparo dos meios, mas estes poderiam ter sido insuficientes. Poder-se-ia supor falha técnica ou que estariam implicados outros agentes que exigissem técnicas particulares de isolamento, como no caso dos vírus.
Vários autores 2123447 têm salientado que a sorologia é um método diagnóstico mais efetivo que o isolamento, uma vez que o cultivo necessita de meios apropriados e tempo de incubação a $37^{\circ} \mathrm{C}$ de 15 a 30 dias, não dando nenhuma contribuição prática quando há necessidade de rápida instalação da terapêutica.

Em trabalho realizado com estudantes da Universidade de Wisconsin, EUA, Evans e cols 12 encontraram maior porcentagem de testes positivos para $M$. pneumoniae pela FC do que por métodos de isolamento ou cultura.

Estudando população de Seatle-USA, Foy e 

jan-mar, 1991

cols 19 não obtiveram nenhum isolamento de $M$ pneumoniae, em determinado período do ano, e baixa freqüência de isolamento em outros períodos, mostrando assim que em periodos endêmicos há baixo ou nulo encontro do agente, podendo variar de $2 \%$ nos anos endêmicos e $35 \%$ nos anos epidèmicos ${ }^{18}$. Esses autores $^{18}$ comprovaram que o isolamento foi mais efetivo que a sorologia, em pessoas dos 2 aos 30 anos, mas em crianças mais jovens e adultos idosos metade das infecções foram diagnosticadas somente por métodos sorológicos, acrescentando que em levantamentos, ao não se considerar os casos positivos somente por métodos sorológicos, pode-se cometer erros na estimativa de incidencia de infecção pelo $M$. pneumoniae.

Entre os métodos sorológicos a FC tem sido um dos mais usados e considerada um dos mais sensiveis 10404345 .

Dos 64 pacientes por nós estudados, apenas uma amostra de soro foi colhida em 5 , por ocasião do quadro agudo; a segunda amostra nào foi obtida por causa do não comparecimento ao retorno e tentativa infrutifera de localização no domicílio. Em 4 desses pacientes o título de anticorpos contra $M$. pneumoniae foi $<8$ e num deles o titulo foi de 16 ; a análise desses casos também foi prejudicada.

Como se pode observar na Tabela 2 e de acordo com os critérios adotados pela $\mathrm{FC}$, verificou-se que $87,5 \%$ da população de estudo era não imune para $M$. pneumoniae, tendo sido realizados testes em duas amostras de soro na maioria dos casos. Dos pacientes com duas amostras, $88,13 \%$ foram considerados não imunes; portanto, o quadro respiratório por eles apresentado por ocasião do estudo não deve ter correspondido à infecção por $M$. pneumoniae. Os 4 pacientes com títulos de 16 na fase aguda e na de convalescença (Tabela 2) já teriam apresentado infecção no passado.

Tabela 2 - Reciproca dos títulos de anticorpos para Mycoplasma pneumoniae obtidos por fixaçäo de complemento ( $F C$ ) no soro de 64 individuos com infeccāo respiratória aguda.

\begin{tabular}{cccc}
\hline & $\mathrm{FC}$ & \multicolumn{2}{c}{ Reciproca dos titulos } \\
\cline { 3 - 4 } No de individuos & $(\%)$ & 1. a amostra & 2 2. amostra \\
\hline 52 & $(87,5)$ & $\leqq 8$ & $\leqq 8$ \\
4 & & $<8$ & $\mathrm{ND}$ \\
\hline 1 & & 16 & $\mathrm{ND}$ \\
1 & & 8 & 16 \\
4 & $(12,5)$ & 16 & 16 \\
1 & & $<8$ & 32 \\
1 & & 64 & 64 \\
\hline
\end{tabular}

$\mathrm{ND}=$ não disponivel; $\mathrm{N} \circ=$ número
Um paciente teve título de 8 na 1 a amostra e de 16 na 2a amostra (Tabela 2). Variaçōes de uma diluição em testes sorológicos não são significativos; assim, o quadro respiratório por ocasião do estudo não deve ter correspondido à infecção pelo $M$. pneumoniae.

Dados de literatura18 1933 têm mostrado indices de $4-44 \%$ na vigência de pneumonia devido ao $M$. pneumoniae em diferentes populaçōes; na maioria dos casos o paciente apresenta apenas infecção do trato respiratório alto ou mesmo quadro assintomático10 1317 .

Dois pacientes (Tabela 2) tiveram titulos $<8 \mathrm{e}$ de 32 e 64 e de 64, o que leva a supor que os quadros respiratórios por eles apresentados possam ter correspondido a infecção por M. pneumoniae. Dessa forma a prevalência da infeç̧ão por $M$. pneumoniae diagnosticada pela $\mathrm{FC}$ foi igual a $3,1 \%$.

A prevalência da infecção por $M$. pneumoniae pode sofrer flutuaçōes, dependendo da populaçāo ou do local do estudo, como característica do agente 1019. Assim, em populações de doentes, freqüência da infecção da ordem de $1 \%$ a $16 \%$ tem sido registrada por vários autores 163538 . Freqüência acima de $40 \%$ também foi relatada 71233 .

Estudando no Brasil crianças com zero a 5 anos de idade, com quadros pulmonares, Moreno 34 encontrou soroconversão para $M$. pneumoniae em $60 \%$ dos casos.

Visando-se opção metodológica, decidiu-se comparar a FC com outro teste, no caso a CIE. Essa reação é usada no HCFMRP-USP para diagnóstico de infecção por bactérias e fungos, sendo processada em liquor e soro. Assim, com pequenas modificações foi utilizada para dosagem de anticorpos anti- $M$. pneumoniae neste estudo.

Os dados da literatura relativos ao emprego da CIE para diagnóstico de infecção pelo $M$. pneumoniae são escassos 213244 , o que dificultou a análise dos resultados do nosso estudo. Não há citação de qual seria o título mínimo da reação para que o indivíduo seja considerado não-imune; além disso, quando se usa na CIE o mesmo antígeno empregado na FC, temse encontrado dificuldade para demonstrar linhas de precipitação em diluições do soro acima de 1:421 32 . O mesmo problema foi observado na população de estudo.

Título não reagente pela CIE foi observado em 90,6\% dos pacientes (Tabela 3). Em apenas um paciente $(1,56 \%)$ houve aumento de quatro vezes no titulo de anticorpos na 2a amostra de soro, sendo portanto o único cujo diagnóstico de infecção pelo $M$. pneumoniae pôde ser estabelecido com segurança.

$\mathrm{Na}$ comparação dos dois métodos (Tabela 4), $83,73 \%$ das amostras de soro foram negativas por ambas as técnicas. Em 7,32\% houve positividade pela 
Machado AA, Couch RB, Rossini AJ, Costa JC. Participação do Mycoplasma pneumoniae na etiologia de infeç̧ões respiratórias agudas em Ribeirão Preto, São Paulo, Brasil. Revista da Sociedade Brasileira de Medicina Tropical $24 \cdot 43-50$ jan-mar, 1991

Tabela 3 - Reciproca dos titulos de anticorpos para Mycoplasma pneumoniae obtidos por contra-imunoeletroforese (CIE) no soro de 64 individuos com infecção respiratória aguda.

\begin{tabular}{cccc}
\hline & CIE & \multicolumn{2}{c}{ Reciproca dos titulos } \\
\cline { 3 - 4 } No de individuos & 1\% & 1a amostra & 2a amostra \\
\hline 54 & $(90,6)$ & NR & NR \\
4 & NR & ND \\
\hline 1 & 2 & ND \\
2 & $(9,4)$ & 2 & 2 \\
1 & 1 & 4 \\
2 & & 4 & 4 \\
\hline
\end{tabular}

$\mathrm{NR}=$ não reagente; $\mathrm{ND}=$ não disponivel; $\mathrm{No}=$ número mostrando que há correlação aceitável entre os dois métodos.

Quanto às dosagens realizadas na populaçãocontrole, através dos mesmos métodos sorológicos (FC e CIE), observou-se que em $99 \%$ dos individuos foram não-reagentes pela $\mathrm{FC}$ e em $1 \%$ foram positivos (titulos 16 e 32) pela FC, enquanto pela CIE foram considerados não-reagentes em $90 \%$ dos soros, com titulos que variaram de 1 a 32 (Tabela 5).

Na comparação entre os dois métodos (Tabela 5), 95,5\% foram negativos ou não-reagentes por ambos os métodos. Apenas $0,5 \%$ foi reagente pelos dois métodos (titulo de $32 \mathrm{em}$ ambas as reações). No conjunto, a conegatividade foi de $97 \%$ e a concordância $96 \%$. As copositividades foram baixas sendo FC/CIE de $12,5 \%$ e CIE/FC de $50 \%$, evidenciando-

Tabela 4-Pesquisa de anticorpos para Mycoplasma pneumoniae através de reaçâo FC e CIE, em 123 amostras de soro de individuos com infeç̧ão respiratória aguda: comparação dos resultados dos dois métodos.

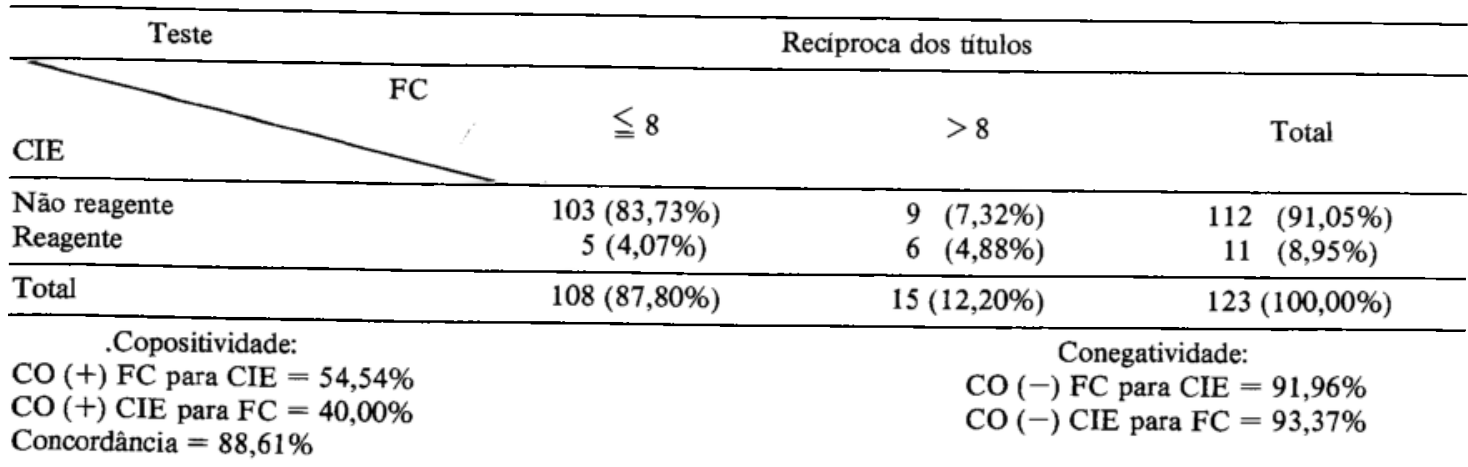

FC e negatividade pela CIE, enquanto em $4,07 \%$ foram negativas pela $\mathrm{FC}$ e positivas pela CIE. A copositividade e conegatividade encontram-se assinaladas na Tabela 4 . A concordância foi de $88,61 \%$ se discrepâncias nos dois métodos para detecção dos positivos (Tabela 5).

A prevalência de anticorpos para $M$. pneumoniae na população-controle foi de $1 \%$ pela FC e de $4 \%$

Tabela 5 - Correlação entre os resultados da pesquisa de anticorpos para Mycoplasma pneumoniae por fixação do comple mento $(F C)$ e contra-imunoeletroforese (CIE) no soro de uma populaçáo-controle de 200 individuos aparentemente normais.

\begin{tabular}{lcccc}
\hline & $\leqq$ & & & \\
Titulos de CIE & Titulos de FC & 16 & 32 & Total \\
\hline Reagente & 7 & 0 & 1 & 8 \\
\multirow{2}{*}{ Não reagente } & $(3,5 \%)$ & 1 & $(0,5 \%)$ & $(4,0 \%)$ \\
& 191 & 1 & 0 & 192 \\
Total & $(95,5 \%)$ & $(0,5 \%)$ & 1 & $(96,0 \%)$ \\
& 198 & 1 & $(0,5 \%)$ & $(100,0 \%)$ \\
\hline
\end{tabular}

Copositividade $\mathrm{FC}$ para $\mathrm{CIE}=12,50 \%$; Copositividade $\mathrm{CIE}$ para $\mathrm{FC}=50,00$; Conegatividade $\mathrm{FC}$ para $\mathrm{CIE}=99,45 \%$;

Conegatividade CIE para $\mathrm{FC}=96,46 \%$.

Concordância $=96,00 \%$.

Prevalência de anticorpos para Mycoplasma pneumoniae: $1 \%$ pela FC e $4 \%$ pela $C I E$. 
pela CIE. Esses resultados assemelham-se aos de outros estudos realizados em populações diferentes quanto à faixa etária e à localidade 118 .

Em vista dos dados obtidos com a metodologia empregada, observa-se que a infecção pelo $M$. pneumoniae na população-controle foi pouco prevalente, o que está de acordo com o baixo índice da doença por esse agente encontrado na população estudada com infecção respiratória aguda.

Através da FC encontraram-se dois pacientes com provável infecção pelo $M$. pneumoniae. Devido ao pequeno número de casos, a análise quanto a idade, sexo e cor ficou prejudicada.

Tosse, febre e coriza foram os sintomas mais comumente encontrados nos dois pacientes. Cefaleia foi relatada por apenas um dos doentes, sendo o sintoma mais encontrado em outras séries na literatura 781620 . Ao exame físico foi comum a ambos o encontro de linfadenopatia cervical e estertores crepitantes. Um dos pacientes apresentava também estertores bolhosos, sendo a semiologia e os raios- $x$ de tórax compatíveis com condensação em base direita $e$ esquerda e derrame pleural à esquerda. Derrame pleural foi relatado em 15 a $20 \%$ dos casos estudados por diferentes autores 141538 . O outro paciente possuia aos raios- $x$ de tórax velamento retículo-nodular em bases, semelhante ao relatado por outros autores 51527 , não raro confundivel com tuberculose como ocorreu, inicialmente, neste caso.

Não há modelo radiológico característico para a pneumonia por $M$. pneumoniae 515 ; a radiografia do tórax pode apresentar-se com padrões variados. Alguns dos nossos pacientes apresentaram raios- $\mathrm{x}$ compatível com a suspeita clínica de infecção pelo $M$. pneumoniae, mas nem o isolamento nem a sorologia confirmaram a hipótese diagnóstica. A melhora radiológica ocorreu entre 15 a 27 dias, dado semelhante aos de outros relatos 45202736 .

Um dos casos teve otalgia e otite média precedendo o quadro, o que é descrito na literatura em $10 \%$ a $30 \%$ dos $\operatorname{casos}^{8} 1727$. Esse caso teve uma terceira amostra de soro colhida 6 meses após o quadro agudo, sendo os títulos semelhantes aos da segunda amostra (1:64 pela FC e 1:4 pela CIE).

Contrariando dados de literatura 2427 , os pacientes do estudo com antecedentes de pneumonia e/ou quadros alérgicos foram soronegativos para anticorpos anti-M. pneumoniae, tanto pela FC como pela CIE.

O diagnóstico de infecção pelo $M$. pneumoniae pode ser suspeitado por dados epidemiológicos e alguns sintomas, mas neste estudo, assim como em outros, evidenciou-se que não existem características clínicas peculiares de infecção pelo $M$. pneumoniae $\mathrm{e}$ os pacientes podem ser erroneamente diagnosticados $\mathrm{e}$ mesmo tratados.

\section{Concluiu-se que:}

1. A prevalência da infecção pelo $M$. pneumoniae na população com infecção respiratória aguda atendida no HCFMRP-USP, no ano do estudo (19861987), foi baixa.

2. A concordância entre as reações de FC e CIE foi aceitável (88,6\% na população de estudo e $96 \%$ na população-controle), porém com discrepâncias entre os dois métodos para detecção de indivíduos com anticorpos presentes no soro.

3. A FC pode ser indicada como teste sorológico preferencial para diagnóstico de infecçāo pelo $M$. pneumoniae em infecções respiratórias agudas e a CIE para emprego em inquéritos soroepidemiológicos.

4. Desde que o diagnóstico sorológico pela FC foi feito somente em dois pacientes com infecção respiratória aguda, o nāo isolamento do $M$. pneumoniae não constitui surpresa.

5. Estudos semelhantes ao que realizamos seriam indicados em outros periodos no mesmo local, para detecção da variabilidade da infecção pelo $M$. pneumoniae em infecção respiratória aguda, bem como em outras regiões, levando ao melhor conhecimento de dados nacionais sobre a prevalência da infecção por esse agente.

\section{SUMMARY}

Mycoplasma pneumoniae isolation was attempted in respiratory fluids from 64 patients with respiratory infection Complement fixation test $(C F)$ and counterimmunoelectrophoresis (CIE) were used for Mycoplasma antibody detection using the patient sera. Mycoplasma pneumoniae was not isolated. Serologic diagnosis were positives in 3,1\% (2/64) by CF test and 1,6\% (1/64) by CIE. Serologic tests done in 200 health controls showed $4 \%$ $(8 / 200)$ positives by CIE and $1 \%(2 / 200)$ by $C F$. The results showed differences in sensitivity among the serologic tests. $C F$ seems to be more indicated for Mycoplasma infection diagnosis while, CIE could be used for Mycoplasmas serosurveys. The prevalence of Mycoplasma pneumoniae infections was low $(3,1 \%)$ in the 64 patients during our study period.

Key-words: Respiratory infection. Mycoplasma pneumoniae. Pneumonia by Mycoplasma. Prevalence of Mycoplasma pneumoniae.

\section{REFERÊNCIAS BIBLIOGRÁFICAS}

1. Agarwal SC, Mahajan RC, Asnani PJ, Ganguly NK. Complement-fixing and immunofluorescent antibodies to Mycoplasma pneumoniae in sera from a normal community. The Indian Journal of Medical Research 59: 861-865, 1971.

2. Ali NJ, Sillis M, Andrews BE, Jenkins PF, Harrison BDW. The clinical spectrum and diagnosis of Mico- 
Machado AA, Couch RB, Rossini AJ, Costa JC. Participação do Mycoplasma pneumoniae na etiologia de infeç̧oes respiratórias agudas em Rịheirão Preto, São Paulo, Brasil. Revista da Sociedade Brasileira de Medicina Tropical 24: 43-50, jan-mar, 1991

plasma pneumoniae infection. Quartely Journal of Medicine, New Series 58 227: 241-251, 1986.

3. Asúa M de, León L, Grinstein S. Diagnóstico sorológico de Mycoplasma pneumoniae en una problación pediàtrica. Revista Hospital dos Ninos 24: 111-114, 1982.

4. Barreto SM, Comiran JH, Gorini CF, Ferriera CT, Rohde LB, Marmontel M. Pneumonia por Mycoplasma pneumoniae: relato de um caso com insuficiência respiratória aguda. Jornal de Pneumologia 8: 93-96, 1982.

5. Cameron DC, Borthwick RN, Philp T. The radiographic patterns of acute mycoplasma pneumonitis. Clinical Radiology 28: 173-180, 1977.

6. Clyde Jr WA. Instroductory remarks. In: Tully JC, Razin S (ed) Methods in Mycoplasmology. Diagnostic mycoplasmology, Academic Press, vol. II, cp A1 p. 3-7, 1983.

7. Copps SC, Allen VD, Sueltmann S, Evans AS. A community outbreak of Mycoplasma pneumonia. The Journal of the American Medical Association 204: 121126, 1968.

8. Couch RB. Mycoplasma diseases. In: Mandel G, Douglas $G$, Bennett $J$ (ed) Principles and practice of infectious disease, 2nd edition, John Wiley, New York p. 10641076, 1985.

9. Crawford YE. A laboratory guide to the mycoplasmas of human origen, 2 nd edition, Great Lakes, Naval Medical Research Unit n. 4 p. 1-60, 1972.

10. Denny FW, Clyde Jr WA, Glezen WP. Mycoplasma pneumoniae disease: clinical spectrum, pathophysiology, epidemiology and control. The Journal of Infectious Diseases 123: 74-92, 1971.

11. Edwards EA. Immunologic investigations of meningococcal disease. I. Group-specific Neisseria meningitidis antigens present in the serum of patients with fulminant meningococcemia. The Journal of Immunology 106: 314-317, 1971.

12. Evans AS, Allen V, Sueltmann S. Mycoplasma pneumoniae infections in University of Wisconsin students. American Review of Respiratory Disease 96: 237-244, 1967.

13. Fernald GW, Collier AM, Clyde Jr WA. Respiratory infections due to Mycoplasma pneumoniae in infants and children. Pediatrics 55: 327-335, 1975.

14. Fine NL, Smith LR, Sheedy PF. Frequency of pleural effusions in mycoplasma and viral pneumonias. The New England Journal of Medicine 283: 790-793, 1970.

15. Finnegan OC, Fowles SJ, White RJ. Radiographic appearances of Mycoplasma pneumonia. Thorax 36: 469-472, 1981.

16. Foy HM, Cooney MK, McMahan R, Grayston JT. Viral and mycoplasmal pneumonia in a prepaid medical care group during an eight-year period. American Journal of Epidemiology 97: 93-102, 1973.

17. Foy HM, Grayston JT, Kenny GE, Alexander ER, McMahan R Epidemiology of Mycoplasma pneumoniae infection in families. The Journal of the American Medical Association 197: 859-866, 1966.

18. Foy HM, Kenny GE, Cooney MK, Allan ID. Long-term epidemiology of infections with Mycoplasma pneumoniae. The Journal of Infectious Diseases 139: 681-687, 1979.
19. Foy HM, Kenny GE, McMahan R, Kaiser G, Grayston JT. Mrcoplasma pneumoniae in the community. American Journal of Epidemiology 93: 55-67, 1971.

20. Foy HM, Kenny GE, McMahan R, Mansy AM, Grayston JT. Mycoplasma pneumoniae pneumonia in an urban area. Five years of surveillance. The Journal of the American Medical Association 214: 1666-1672, 1970.

21. Goldschmidt BL, Menonna JP, Dowling PC, Cook SD. Rapid detection of mycoplasma antibody. The Journal of Immunology 117: 1054-1055, 1976.

22. Greenwood BM, Whittle HC, Dominic-Rajkovic O. Counter-current immunoelectrophoresis in the diagnosis of meningococcal infections. The Lancet 2: 519-521, 1971.

23. Kitamoto $\odot$, Nakamura S, Ebisawa I, Sato T. Mycoplasma pneumoniae infection in atypical pneumonia in the Tokyo area. The Japanese Journal of Experimental Medicine 36: 291-299, 1966.

24. Lambert HP. Antibody to Mycoplasma pneumoniae in normal subjects and in patients with chronic bronchitis. The Journal of Hygiene 66: 185-189, 1968.

25. Lehtomäki K. Rapid etiological diagnosis of pneumonia in young men. From Central Military Hospital, Helsinki 1988. Scandinavian Journal of Infectious Diseases 54 (suppl); 4-56, 1988.

26. Lennette $E H$, Schmidt NJ. Complement fixation test. In: Lennette EH, Schmidt NJ (ed) Diagnostic procedures for viral and rickettsial infections, $3{ }^{a}$ edition, American Public Health Association, Inc, New York p. 37-38, 1964.

27. Levine DP, Lerner AM. The clinical spectrum of $M y c o-$ plasma pneumoniae infections. The Medical Clinics of North America 62: 961-978, 1978.

28. Levy CE. Contraimunoeletroforese e hemaglutinação passiva como métodos complementares para o estudo da infecção meningocócica. Tese de mestrado, Faculdade de Medicina de Ribeirāo Preto, Universidade de São Paulo, Ribeirão Preto, 1978.

29. Lind K. Isolation of Mycoplasma pneumoniae (Eaton Agent) from patients with primary atypical pneumonia. Acta Pathologica Microbiologica Scandinavica 66: 124 134, 1966.

30. Maassab HF, Steinhoff MC. Viral sorology the complement fixation test (microprocedure). In: Manual of Laboratory procedure for diagnosis of respiratory virus infection Michigan, Bostid Research Grants Program on Etiology and Epidemiology of Acute Respiratory Infections in Children, s.d., cp 7, p. 7-6, 7-15, 1986.

31. Márdh PA, Taylor-Robinson D. New approaches to the isolation of mycoplasmas. Medical Microbiology and Immunology 158: 259-266, 1973.

32. Menonna J, Chmel H, Menegus M, Dowling P, Cook S. Precipitating antibodies in mycoplasma infection. Joumal of Clinical Microbiology 5: 610-612, 1977.

33. Mogabgab WJ. Mycoplasma pneumoniae and adenovirus respiratory illnesses in military and University personnel 1959-1966. American Review of Respiratory Disease 97: 315-358, 1968.

34. Moreno NO. Envolvimento do $M$. pneumoniae em quadros de pneumopatias em crianças na faixa etária 0-5 
Machado AA, Couch RB, Rossini AJ, Costa JC. Participação do Mycoplasma pneumoniae na etiologia de infeç̧óes respiratórias agudas em Ribeirão Preto, São Paulo, Brasil. Revista da Sociedade Brasileira de Medicina Tropical 24: 43-50, jan-mar, 1991

anos. Tese de mestrado, Universidade de São Paulo, São Paulo, 1985.

35. Mufson MA, Krause HE, Mocega HE, Dawson FW. Viruses, Mycoplasma pneumoniae and bacteria associated with lower respiratory tract disease among infants. American Journal of Epidemiology 91: 192-202, 1970.

36. Nasi LA, Gus M, Von Eye H, Vinicius Netto M, Barreto SM. Pneumonias por agentes filtráveis. Relato de um caso de infecção por Mycoplasma pneumoniae e revisão prática do tema. Jornal Brasileiro de Medicina 46: 65$71,1984$.

37. Pearce J, Bettleheim K, Metcalfe R. Antibody levels to Mycoplasma pneumoniae in sera collected from healthy blood donors of Wellington, New Zealand, during 19761980. The Journal of Hygiene 96: 249-255, 1986.

38. Pönkä A. Clinical and laboratory manifestations in patients with serological evidence of Mycoplasma pneumoniae infection. Scandinavian Journal of Infectious Diseases 10: 271-275, 1978.

39. Pönkä A. Occurrence of serologically verified $\mathrm{Myco-}$ plasma pneumoniae infections in Finland and in Scandinavia in 1970-1977. Scandinavian Journal of Infectious Diseases 12: 27-31, 1980.

40. Purcell RH, Chanock RM. Mycoplasmas of human origin. In: Lennette EH, Schmidt NJ (ed) Diagnostic procedures for viral and ricketsial infections, 4th edition, American Public Health Association, Inc, New York p. 786-825,1969.

41. Razin S. Characteristics of the mycoplasmas as a group. In: Razin S, Tully JG (ed) Methods in Mycoplasmology, New York, Academic Press, vol. I, Section A p. 3-7, 1983.
42. Rossini AJ. Contribuição ao estudo de micoplasmose bovina. Padronização da reaçāo de contraimunoeletroforese para a pesquisa de anticorpos séricos contra Mycoplasma bovis. Tese de doutorado, Universidade de São Paulo, São Paulo, 1982.

43. Salles Gomes LF, Takimoto S, Freitas Jr JO. $\mathrm{Myco}^{-}$ plasma pneumoniae: freqüência da infecção em grupos etários da populaçāo da capitale do interior do Estado de São Paulo. Revista do Instituto de Medicina Tropical de São Paulo 17: 20-26, 1975.

44. Semenova VA, Stetsenko OG, Baimuratova MA, Baijamortov MS. Rapid diagnosis of Mycoplasma pneumoniae infection by the counterimmunoelectrophoresis reaction. Laboratornoe Delo 5: 291-293, 1986.

45. Taylor-Robinson D, Shirai A, Sobèslavský O, Chanock RM. Serologic response to Mycoplasma pneumoniae infection. II. Significance of antibody measured by different techniques. American Journal of Epidemiology 84: 301-313, 1966.

46. Taylor-Robinson D, Soběslavský O, Jensen KE, Senterfit LB, Chanock RM. Serologic response to Mycoplasma pneumoniae infection. I. Evaluation of immunofluorescence, complement fixation, indirect hemagglutination, and tetrazolium reduction inhibition tests for the diagnosis of infection. American Journal of Epidemiology 83: 287-298, 1966.

47. Vikerfors T, Brodin G, Grandien M, Hirschberg L, Krook A, Pettersson CA. Detection of specific IgM antibodies for the diagnosis of Mycoplasma pneumoniae infections: a clinical evaluation. Scandinavian Journal of Infectious Diseases 20: 601-610, 1988. 